\title{
Creating a Culture Together: Intercultural Relationships and Communication
}

\author{
Tianna Leung ${ }^{1}$
}

\begin{abstract}
This paper discusses the different cultural factors that exacerbate relationship stressors in intercultural relationships. I begin by providing some historical context that has influenced society's outlook on intercultural relationships. I then provide a literature review that explores current studies on intercultural similarities and differences, effective coping strategies, and possible modifications in couples' therapy. I argue that increasing communication within intercultural relationships will allow partners to create a culture of their own. Finally, I suggest that professionals should require education in different cultural backgrounds to provide safe, accurate, and successful couples' therapy.
\end{abstract}

\footnotetext{
${ }^{1}$ MacEwan University
} 


\section{Introduction}

The number of intercultural relationships and marriages continues to rise in Canada. In a 2011 National Household Survey, Statistics Canada reported that $4.6 \%$ of all marriages or common-law relationships in Canada were mixed unions. This was a noticeable increase from the statistics taken in 1991 when they reported mixed unions comprising $2.6 \%$ of all couples. Statistics Canada defines mixed unions as relationships in which one, or both, partners are part of a visible minority group (Statistics Canada, 2018). Similarly, mixed union marriages and common-law relationships are on the rise in many globalized countries. The increase in globalization has led to different cultures coming into contact with one another which ultimately leads to mixed union relationships (Bustamante et al., 2011, p. 154). These relationships between individuals of different cultures are often referred to as interracial relationships, mixed unions, or intercultural relationships. Although none of these terms are incorrect, in this paper I focus on the broader aspects of culture that may be neglected when reducing these relationships to race and ethnicity. The term culture encompasses all the values, beliefs, morals, habits, traditions, practices, and norms of a social group (Fonseca et al., 2020, p. 3). Therefore, for this paper, I will refer to mixed unions as intercultural relationships.

Historically speaking, contact between different cultures resulted in hostility and conflict. Although views on cultural incompatibility are much less extreme, it is important to acknowledge that intercultural couples will inevitably have different conflicts to overcome than individuals from the same culture. Intercultural couples have additional external and internal stressors in their relationship that, if left unaddressed, will cause them to clash more than other couples. Additionally, an individual's cultural background will impact how they perceive and manage conflicts with their partner (Tili \& Barker, 2020, p. 190). Researchers have also found that couples can benefit from therapy most when the therapeutic approach is aligned with their worldviews (Linhof \& Allen, 2019, p. 45). Thus, the different components of culture must be taken into account when analyzing intercultural relationships. Research also suggests that viewing culture as dynamic, rather than static, allows you to see how relationships can evolve through communication, which always results in compromise and negotiation (Tili \& Barker, 2020, p. 191). In this paper, I hypothesize that increasing communication and openness between partners will allow couples to create a culture together, thus improving the overall functioning of intercultural couples. Also, I address the changes that need to be made to couple's therapy to maximize the benefits for intercultural couples.

\section{Historical Views on Intercultural Marriage}

Before I introduce the research, I believe it is important to reflect on how historical views on intercultural marriages may affect current intercultural marriage practices. Throughout the history of Canada, numerous cultural groups were forced to assimilate by British colonizers. This was validated through the formation of social constructs that labeled people from differing cultures as threats to white racial purity. (Killian, 2012, p. 125). Homogamy survived under the creation of false pretenses and stereotypes created about non-white individuals. A long history of sensationalizing racial bias and ethnocentric views caused many to reduce all problems in current 
intercultural relationships to racial differences. In a study by Killian (2012), the findings showed that individuals in intercultural relationships chose to ignore sensitive topics such as racism and oppression as it brought tension to the relationship (p. 129). Moreover, when one partner was forced to address situations of discrimination or oppression, they often felt they are being oversensitive and making the other partner uncomfortable (Killian, 2012, p. 130). Therefore, many couples may unknowingly resort to acculturation, where one partner conforms to the other culture. However, this causes stress on the individual who has to conform and may result in more underlying issues in the relationship. People often say they are blind to their partner's difference, but ignorance can cause deeper, unresolved, conflict. Therefore, I suggest ways in which intercultural couples can work through conflict and evolve with one another.

\section{Literature Review}

Multiple studies have shown inherent differences between the stressors that impact couples from the same backgrounds and the stressors that intercultural couples have to undergo. In a study by Bustamante et al. (2006), using a phenomenological approach, they interviewed intercultural couples for analysis. From the interviews, they identified common stressors in intercultural relationships and the conscious and unconscious coping mechanisms that these couples use to overcome conflict. The common stressors identified by the participants are 1) child-rearing practices; 2) time orientation; 3) gender-role expectations; and 4) extended pressures from family members (Bustamante et al., 2011, p. 6). Although many of these stressors are common amongst same-culture couples, their stress is often enhanced by external factors relating to cultural practices and beliefs. Disagreements on parenting style and discipline was an agreeable stressor for most couples, as cultural differences directly impacted the values and practices that were implemented on their children. Individuals also reported differences in time management with some individuals being used to moving at a faster pace than their partners.

In particular, gender-role stressors were related to the traditional gender roles in the country that the male partner identifies with, and often resulted in stringent restrictions on the role of the female in the household. The final stressor, extended stressors from family members, can differ from same-culture couples in terms of familial acceptance or language barriers between a partner and their in-laws. (Bustamante et al., 2011, pp. 161-162). The study also ruled out four coping mechanisms that intercultural couples use whether it is done consciously or unconsciously. These coping strategies are 1) gender role flexibility; 2) humour; 3) cultural deference by one partner and 4) cultural reframing or the development of blended values and expectations (Bustamante et al., 2011, p. 159). A key component to gender role flexibility was communicating expectations between partners. Humour was commonly used to offset tension after talking through differences. However, partners often reported cultural deference in which one partner would defer to the other's culture. As previously mentioned, cultural deference may not be the most effective strategy in the long-term. Finally, cultural reframing consists of couples accepting each other's cultural differences and establishing new values, beliefs, and practices together (Bustamante et al., 2011, p.161). Overall, the study revealed four important coping strategies with communication as a key component. 
There are many differences between cultures, some more salient than others. For example, native language or holiday traditions. Because these differences are more observable, they are more commonly acknowledged between partners. However, some differences are covert and act as the driving force behind our cultural practices and habits. A study by Tili \& Barker (2020) examined the communication between Asian and American intercultural couples. From the study, they determined that a large driving force that largely impacts their cultural practices is whether they identify with a collectivist or individualist culture. They found that individualist and collectivist cultures differ greatly in how they communicate and handle conflict. Conflict styles differed in a few notable ways. Individuals with collectivist values preferred a more avoidant approach, whereas partners with individualist values preferred a more direct approach (Tili \& Barker, 2020, p. 193). They also differ in how they express emotions. Collectivists express symbolically and individualists explicitly express (Tili \& Barker, 2020, p. 196). After interviewing the couples, they found personal growth, language fluency, and high-context/low-context styles to be the most common factors that improve communication amongst the couples. Personal growth within an individual partner encouraged them to want to achieve effective communication with their partner. Partners found that as a person they became more accepting of other couples once they communicated more with their partner. They also found that language-fluency acted as an obstacle to achieving effective communication. Finally, those who value high-context styles expected more expressive responses from partners, while low-context partners avoided dramatic expression (Tili \& Barker, 2020, p. 203). In general, the study aimed to show differences in emotional processes affect communication between intercultural couples.

A reoccurring idea that new research on intercultural relationships seems to agree on is the importance of focusing on cultural similarities rather than differences. One study in particular, by Fonseca et al. (2020), focuses on the similarities in relationship goals between intercultural couples. They define relationship goals as the definition of romantic love, expression of love, and conflict style. The study analyzed the passive or active responsiveness of intercultural couples and indicated how their styles of responsiveness were used to mediate conflict (Fonseca et al., 2020, p. 6). They found that accurate responsiveness to conflict is more easily accomplished when individuals were similar to their partners in how they perceive and express emotions, such as their relationship goals. Another finding was that couples who were together longer were more similar in their perception and expression of emotions. Thus, their results demonstrated that couples may benefit from adopting a shared set of cultural values and beliefs that define what their relationship goals are (Fonseca et al., 2020, p.17).

In another study by Seshadri \& Knudson-Martin (2011) they performed a grounded theory analysis, using coding, to study how intercultural couples manage their intercultural differences (Seshardri \& Knudson-Martin, (2011), p. 43). The study yielded four relational strategies: creating we, framing differences, emotional maintenance, and how couples position themselves with others $^{2}$ (Seshardri \& Knudson-Martin, (2011), p. 49). The study found that successful relationships were reliant on how couples organized around their differences and the on-going relationship strategies they used. Moreover, the most successful strategy used to work-through differences was showing interest in their partner's cultures (SeShardi \& Knudson-Martin, 2011, p. 52).

\footnotetext{
${ }^{2}$ See Seshardri \& Knudson-Martin (2011), for more information on the study.
} 
As we can see there are many different areas of conflict that can arise in intercultural relationships. Nonetheless, the increase in the prevalence of intercultural relationships means it is important to find effective ways for these couples to overcome intercultural challenges. A study conducted by Halzapfel et al. (2018) analyzes the correlation between internal stress, dyadic coping, and relationship satisfaction. Their study shows how communicating stress to one's partner, and receiving support from a said partner, can alleviate stress. On the other hand, their study also described the reverse in which internal stress can lead to dyadic stress, due to interdependence. In the study, they revealed positive dyadic coping styles which will help decrease relationship stress and increase dyadic coping. These positive dyadic coping styles include emotion-focused supportive dyadic coping, problem-focused dyadic coping, and delegated dyadic coping. Emotion-focused supportive dyadic coping describes showing support for the other partner, problem-focused dyadic coping involves making suggestions to help the other partner, and delegated dyadic coping refers to taking responsibility to help reduce your partner's stress (Halzapfel et al., 2018, p. 148). In contrast, negative dyadic coping refers to unhealthy coping styles such as distancing oneself from their partner (Halzapfel et al., 2018, p. 149). Due to interdependence, regardless of the stress is on the individual or between partners, the other partner will still be negatively affected by the stress. However, Halzapfel et al.'s (2018) results showed a linear association between the use of positive dyadic coping and increased relationship satisfaction, as well as an association between negative dyadic coping and decreased relationship satisfaction (Halzapfel et al., 2018, p. 154).

Clinical practice on intercultural relationships can provide further insight into how couples can work through their conflicts to better their relationship. However, current clinical practices are catered towards same-culture couples (Linhof \& Allen, 2019, p. 44). Linhof \& Allen (2019) suggest expanding emotionally focused therapy to address how multiple cultural backgrounds exacerbate common stressors in relationships. In the past, a therapist's ignorance of an unknown cultural background may cause a partner to conform to certain norms. They argue that individuals from different cultural backgrounds have other social-political stressors that require better therapist understanding to address the conflict (Linhof \& Allen, 2019, p. 45).

Another clinical practice that is directed towards intercultural relationships is the Visible and Invisible Differences and Similarities grid, proposed by Nguyen et al. (2016). As shown in their case study, partners are asked to place their similarities and differences on a grid, which can be used to help partners visualize their similarities and differences. More importantly, the grid provides visualization on how these traits can change through personal growth and relationship development (Nguyen et al., 2016, p. 216).

Overall researchers have provided extensive findings on the different stressors, particular to intercultural couples, that may cause conflict. Consequently, current couples therapy practices must be modified to be inclusive of all cultural values and beliefs.

\section{Cultural-Specific Stressors}

Every couple faces challenges and obstacles within their relationships. However, studies suggest that intercultural couples are at a higher risk of experiencing conflict, tension, and dissatisfaction due to the impacts of different cultural influences (Fonseca et al., 2020, p. 2). If 
these issues are left unaddressed, they may be detrimental to the relationship. Stress in a relationship not only affects the individual who perceives the stressor first-hand but research has shown that interdependence in relationships results in internal stress between partners (Holzapfel et al., 2018, p. 146). To increase the longevity and success of intercultural relationships, we must first understand the aspects of culture that drive, operate, and motivate individuals in their relationships (Fonseca et al., 2020, p. 3).

One type of stress that is specific to intercultural couples is stress at a macrocultural level. Macrocultural stressors are external factors that include any social constructs or familial reactions that will negatively impact the couple (Bustamante et al., 2011, p. 155). Often, these sociopolitical stressors are rooted in the historical backgrounds of different cultures such as immigration, acculturation, racism, and negative stereotypes (Linhof \& Allen, 2019, p. 44). The negative stigma surrounding intercultural relationships is unique to these couples, and because the prevalence of intercultural relationships only makes up a small fraction of all couples, they will continue to face a lot of discrimination. Society continues to hold the view that there is an underlying oppressive message surrounding the motivation for intercultural relationships. Minority groups may argue that the minority partner is failing their culture by submitting to the oppressor, henceforth they will interpret intercultural relationships as an act of rebellion against their culture (Linhof \& Allen, 2019 , p. 45). Not having familial support can lead to the loneliness of the partners in the relationship, and may cause resentment towards the other partner. Many couples believe that they can ignore these external influences on their relationship, however, not having an external support system will ultimately weigh on an individual and affect their relationship satisfaction.

Alternatively, a partner's family may offer conditional support for the relationship. However, this external acceptance is only granted under the impression that one partner is willing to acculturate to the other culture (Linhof \& Allen, 2019, p. 45). Traditionally, the individual who conforms is the minority partner, and this assumption is made based on historical assimilation. Early research on assimilation suggests that minority group members either assimilate or retain their native culture, but both were not possible (Tili \& Barker, 2020, p. 191). Another related issue is the language barriers between one partner's family and the other partner. In the study by Bustamante et al., (2020), they found language barriers between a partner and their in-laws to be one of the main stressors in intercultural relationships. This created a disconnect between the partner and in-laws and often left the partner from the minority group feeling pressured to accept English as their native language (p. 159). Many minority group members still carry the belief that the only solution is to conform, and this sacrifice can cause underlying bitterness.

Apart from macrocultural influences, a large source of intercultural relationship tension is due to microcultural factors. Microcultural factors include differences in the values, beliefs, and practices of other cultures (Bustamante et al., 2012, p. 155). These factors are the main driving forces of how a partner will act and react in a relationship, and these differences can vary tremendously cross-culturally. One major fundamental difference between cultures, that many pieces of research agreed upon, is the difference between individualist cultures and collectivist cultures. For this paper, I will focus on how individualists and collectivists differ in expressive and communication styles. Whether a partner identifies with collectivist values or individualist values will impact how they perceive their partner's actions and how they will respond. The differences in their expression and response styles can lead to misconceptions and misunderstandings about 
their partner.

One key factor of communication is emotional processing. Newer research findings illustrate that emotions are culturally nuanced, and therefore how they are expressed and interpreted depends on whether a partner values individualism or collectivism (Fonseca et al., 2020 , p. 5). Individualists tend to express their emotions through low-context communication. This means that they believe that direct, verbal communication is the most effective. In contrast, collectivists tend to conform to high-context modes of communication. This entails contextual, non-direct cues, and relates to the belief that confrontation threatens group harmony (Tili \& Barker, 202, p. 193). As a result, communication between intercultural partners becomes misconstrued when the individualistic partner feels threatened when they feel their partner is acting abrasively. Alternatively, dissatisfaction happens when the partner who practices collectivism becomes frustrated that their partner is showing little regard for what they are saying. For these reasons, differences in emotional processing between individualist partners and collectivist partners become a common point of discontent.

Empirical studies have also found a difference between collectivist and individualist cultures in how they express affection. In intimate intercultural relationships, understanding the affectionate style of your partner will lead to less uncertainty and confusion. In general, partners from individualistic cultures place stronger importance on looking for romantic love as a foundation for a family, whereas partners from collectivistic cultures look for intimacy within their family structure and do not require strong romantic intimacy for marital satisfaction (Dion \& Dion, 1993, as cited in Tili \& Barker, 2020, p. 194). If these differences are left undiscussed, the discrepancy between what a partner wants from the other partner can be enough to dismantle a relationship.

In general, intercultural couples face many more adversities in their relationship than sameculture couples. If these challenges are ignored, they may manifest into bigger problems longterm. Therefore, we must assess how we can improve the quality of intercultural relationships. I will now discuss how good communication is one of the best strategies for dyadic coping in intercultural relationships.

\section{Dyadic Coping Through Communication}

Forming effective communication practices will alleviate a lot of the stress, that is brought upon by cultural differences, in intercultural relationships. Many of the problems, previously discussed, are a result of lack of communication. The study by Halzapfel et al. (2018), found that partners communicating their stress to one another, through stress communication, was one of the top predictors of marital outcome (Halzapfel et al., 2018, p. 148). Stress communication occurs when partners express their stresses to their partners, and positive stress communication often leads partners to realize that the source of stress is coming from their cultural differences as opposed to personality traits in their partner (Halzapfel et al., 2018, p. 157). When partners become aware of the sources of their struggles, they can take effective action in reducing the relationship stress. Similarly, Seshardri \& Knudson-Martin (2013), found that communicating openly about how each partner deals with stress resulted in greater satisfaction (as cited in Halzapfel et al., 2018, p. 145). As discussed in the section above, microcultural stressors, such as differences in emotional 
expression, can be improved by communicating feelings of stress. Communicating how one deals with stress will relieve the other partner of any concern as to how their partner is coping. If both partners practice stress communication, then they will not have to assume how the other partner is feeling. Ultimately, stress communication will reduce a lot of grey-area, or areas of uncertainty, regarding the feelings of the other partner. However, communication is not one-sided, effective communication is also reliant on the responsiveness of the other partner.

Constructive responsiveness refers to a partner's reciprocal response to the other person's stress. Constructive responses consist of active responses and passive responses. Active responses, such as responder expressing involvement, is more beneficial when partners are openly expressive with emotions. Passive responses are more subtle contextual responses, such as listening intently, which assures the other partner they have support (Fonseca et al. 2020, p. 6). Both styles of responsiveness provide the necessary reciprocation in communication between partners. In addition, constructive responsiveness is not limited to an individual's response to their partner's stressors. Fonseca et al. (2020) determined that greater relationship satisfaction is found when partners constructively respond to each other's positive and negative emotional events (p. 6).

Overall, communication is a major solution to solving conflicts in intercultural couples. Without effective communication, individuals who are unfamiliar with their partner's cultural values may misunderstand their partner's actions and motives in a relationship. Ultimately, this will lead to unresolved conflict. Effective communication is not limited to one person verbally expressing their concern, it is equally reliant on the other partner's constructive and empathetic responses (Tili \& Barker, 2020, p. 192).

\section{Creating a Culture Together}

Past research on intercultural relationships suggests that intercultural differences are static as opposed to dynamic and everchanging. Thus, it was commonly believed that acculturation was the only source of compromise in intercultural relationships (Casmir, 1999, as cited in Tili \& Barker, p. 191). However, I strongly believe that effective communication in intercultural relationships will allow them to create a functioning culture together, where partners do not have to make sacrifices that would compromise their cultural values and beliefs.

One important aspect of creating culture together in addressing differences and embracing similarities between the different cultural backgrounds. Through communication, partners can discuss differences and learn to adapt accordingly. Talking through specific aspects of different cultures results in intercultural sensitivity, and partners will be less critical of each other's differences (Seshardi \& Knudson-Martin, 2011, p. 13). Another benefit of discussing similarities and differences is discovering similar goals. Having similar goals will encourage partners to commitment and loyalty amongst partners, subsequently resulting in a deeper relationship (Seshardi \& Knudson-Martin, 2011, p. 49). Finding similarities between cultures allows relationships to build on a strong foundation based on similar beliefs and values. As a result, intercultural couples will face fewer cultural related conflicts, which should increase the longevity and quality of these relationships. 
Once couples understand the differences and similarities within each other's cultures, they can reframe their culture-related stressors. Reframing refers to the act of creating new values, rules, and customs that serve to ameliorate conflict and maintain successful intercultural relationships (Bustamante et al., 2011, p. 191). Furthermore, reframing demonstrates that cultural influences are in fact static, and can allow intercultural partners to develop a culture together.

Once again, I highly suggest that creating a third culture will provide the most beneficial outcome for intercultural relationships.

\section{Suggested Therapy Approaches}

Due to the commonality of inter-relational conflict couples often seek therapy to work through their difficulties. In this final section, I will briefly discuss the importance of adjusting therapeutic approaches so that they take into account cultural influences on intercultural relationships. Current therapy caters to same-culture partners, this approach focuses on differences that are subjective to the individual and separate cultural influences. Therapists have attempted to justify using Emotionally Focused Therapy (EFT) as a one-size-fits-all model when assessing client relationships (Linhof \& Allen, 2019, p. 45). However, this is not beneficial for intercultural couples. As I have discussed, cultural backgrounds drive our motives, behaviours, and responses of individuals, by disregarding them we neglect to target the root of the problem. Researchers have also found that couples are most likely to report benefitting from therapy when the approach fit their world views (Johnson \& Talitman, 1997, as cited in Linhof \& Allen, 2019, p. 44) For that reason, to host an appropriate therapy session, professionals must be educated in the different cultural belief systems that may affect a couple's relationship.

Professionals must also be wary of their own cultural bias as it may result in the further marginalization of the minority partner. Professionals must also be aware of their privilege and understanding of the client's multicultural attributes to avoid enforcing their own belief system and oppressing the client (Killian, 2012, p. 124). A therapist may unknowingly favour the side of the partner they share the most values with, and rely on socially constructed norms when assessing the partner they share the least values with. Furthermore, issues of privilege and oppression may come up when assessing intercultural relationships where one partner is part of a minority group. These areas are particularly sensitive for individuals and require professionals who can provide insight and assistance without letting their privileged positions interfere with their work. They must also be cautious that they are not forcing individuals to discuss sensitive topics (Nguyen et al., 2016, p. 219).

Finally, researchers have increasingly encouraged a similarities-focused approach. This allows couples to readjust their mindset and focus on their commonalities, which tend to be much more positive factors. In particular, Nguyen et al. (2016), suggests a grid system in which partners will jot down their similarities and differences. Professionals are encouraged to promote culture as a non-binary system that can develop and change through personal growth and relationship development. By using a grid, couples can see visual changes in their growth as they continue to increase in their similarities overtime (Nguyen et al., 2016, p. 216). 


\section{Conclusion}

The rate of intercultural couples is continuing to increase with every year. However, these couples are more likely to encounter dissatisfaction due to their differences in cultural beliefs, values, and practices. Different cultural factors subsequently cause strain on intercultural relationships that must be eradicated to preserve the relationship. I suggest that effective communication practices will help relieve much of the ongoing stress in intercultural relationships, hence promoting fulfillment and satisfaction. I encourage intercultural couples to further their communication and challenge the belief that one partner must assimilate to have a successful relationship. By creating their own culture together, intercultural couples are not obligated to abandon their own cultural beliefs, which tends to result in resentment towards the other partner. Finally, professionals must be educated in multicultural belief systems to provide appropriate and effective couples therapy. 


\section{References}

Bustamante, R. M., Nelson, J. A., Henriksen, R. C., Jr., \& Monakes, S. (2011). Intercultural couples: Coping with culture-related stressors. The Family Journal, 19(2), 154-164. https://doi.org/10.1177/1066480711399723

Fonseca, A. L., Ye, T., Curran, M., Koyama, J., \& Butler, E. A. (2020). Cultural similarities and differences in relationship goals in intercultural romantic

Fonseca, A. L., Ye, T., Koyama, J., Curran, M., \& Butler, E. A. (2020). A theoretical model for understanding relationship functioning in intercultural romantic couples. Personal Relationships. https://doi.org/10.1111/pere.12349. Journal of Family Issues. https://doi.org/10.1177/0192513X20929071

Holzapfel, J., Randall, A.k., Tao, C., \& Masumi Iida. (2018). Intercultural couples’ internal stress, relationship satisfaction, and dyadic coping. Interpersona: An International Journal on Personal Relationships, 12(2), 145-163. https://doi.org/10.5964/ijpr.v12i2.302

Killian, K. D. (2012). Resisting and complying with homogamy: Interracial couples' narratives about partner differences. Counselling Psychology Quarterly, 25(2), 125-135. https://doi.org/10.1080/09515070.2012.680692

Linhof, A. Y., \& Allan, R. (2019). A narrative expansion of emotionally focused therapy with intercultural couples. The Family Journal, 27(1), 44-49. https://doi.org/10.1177/1066480718809426

Nguyen, H. N., D’Aniello, C., \& Hayes, B. (2016). Exploring visible and invisible differences and similarities in couple therapy. Journal of Family Psychotherapy, 27(3), 215-220. https://doi.org/10.1080/08975353.2016.1199771

Seshadri, G., \& Knudson, M. C. (2013). How Couples Manage Interracial and Intercultural Differences: Implications for Clinical Practice. Journal of Marital \& Family Therapy, 39(1), 43-58. https://doi.org/10.1111/j.1752-0606.2011.00262.x

Statistics Canada. (2018, July 25). Mixed Unions in Canada. Statistic Canada. https://www12.statcan.gc.ca/nhs-enm/2011/as-sa/99-010-x/99-010-x2011003_3-eng.cfm

Tili, T. R., \& Barker, G. G. (2015). Communication in intercultural marriages: Managing cultural differences and conflicts. Southern Communication Journal, 80(3), 189-210. 